\title{
The Association of Self-Reported Iron and Vitamin D Levels on Sleep Quality and Pain Perception in a Subset of Saudi Population
}

\author{
May Wathiq Al-Khudhairy (D' \\ AlAnoud AlOtaibi ${ }^{2}$ \\ Latifa AbdulRahman ${ }^{2}$ \\ Maha Al-Garni $\mathbb{D D}^{2}$ \\ Rahaf Yaslam (iD ${ }^{2}$ \\ Rana Fatani ${ }^{2}$ \\ 'Oral Biology, Department of Oral \\ Maxillofacial Surgery and Diagnostic \\ Sciences, College of Dentistry, Riyadh \\ Elm University, Riyadh, Saudi Arabia; \\ ${ }^{2}$ Riyadh Elm University, Riyadh, Saudi \\ Arabia
}

Background and Aims: There has been a rising concern regarding the relationship of iron levels, vitamin $\mathrm{D}$, and consumption of multivitamins on pain perception and sleep quality. The purpose of this study is to shed light on these connections in hopes of enhancing quality of sleep. Methods: A cross-sectional analysis was used, and data collection was based on closeended online questionnaire created on Survey Monkey. The survey included an operator designed questionnaire, questions from both the Brief Pain Inventory and Sleep Quality questionnaires. The targeted population was participants who were medically fit, nonpregnant Saudi citizens aged between 25 and 55 years.

Results: Prior to the COVID-19 crisis, data were collected during the months of February and March 2020, with a grand total of 3127 participants, out of which 2774 responses were included. The outcome of the research revealed that diminished levels of vitamin $\mathrm{D}$, and iron had a negative impact on sleep quality. In turn, poor sleep quality had a significant pain response.

Conclusion: This study reveals the detrimental role of vitamins on sleep, and their concurrent domino effect on pain.

Keywords: daylight, iron, pain, sleep quality, vitamin D

\section{Introduction}

Sleep is taking the world by storm. Sleep medicine took a leap forward in the early 2000s. Many conditions were discovered and found to be quite common in the general population. ${ }^{1}$ Sleep quality per se is related to an individual's subjective feeling of energy and activity to take on the challenges of a new day. ${ }^{2}$

According to the national sleep foundation, one's need for sleep varies depending on age and gender. The circadian clock controls the daily sleep-wake cycle. Disturbance to this during stressful work schedules, work- or school-related deadlines, jet lag, and other environmental factors cause a tip in the balance, ultimately affecting one's health. ${ }^{3}$

In 1948, health as described by the World Health Organization was "a state of complete physical, mental and social well being and not merely the absence of disease or infirmity". ${ }^{4}$ There is a plethora of evidence documenting the adverse effects to health in response to poor sleep..$^{5-7}$

In recent years, we have found a correlation between the levels of vitamin $\mathrm{D}$ and iron on the quality of sleep. ${ }^{8}$ Unlike other vitamins, vitamin $\mathrm{D}$ is fat soluble and can be absorbed from diet or ultraviolet-B (UVB) radiation. A known
Correspondence: May Wathiq Al-Khudhairy Tel +966503476722

Email may_al-khudhairy@post.harvard.edu; may.alkhudhairy@Riyadh.edu.sa 
indicator for vitamin D status in the body is the 25hydroxyvitamin D $(25(\mathrm{OH}) \mathrm{D})$, which varies according to factors such as sunlight exposure, skin color and lifestyle. Vitamin D receptors are located in areas of the brain that regulate the sleep-wake cycle such as the hypothalamus. Various observational studies have proven an association between sleep disorders and vitamin D deficiency. According to the Epworth Sleepiness Scale (EES), an instrument for measuring excessive daytime sleepiness, McCarty et al observed that patients with vitamin D deficiency scored higher. ${ }^{9}$ In addition, epidemiological data confirms that optimal vitamin $\mathrm{D}$ intake from the diet was associated with longer sleep duration and maintenance of sleep. ${ }^{5}$

Vitamin D deficiency occurs when serum $25(\mathrm{OH}) \mathrm{D}$ is lower than $25 \mathrm{nmol} /$. This deficiency is prevalent in the East including the Middle East, India and the Far East such as China and Mongolia. Those at risk of vitamin $\mathrm{D}$ deficiency are those born with low birth weight, adolescents and pregnant women. Prevention is the best method to overcoming vitamin D deficiency by raising awareness and implementing supplementation in the diet such as in food staples like bread and milk. Furthermore, absorption of vitamin D can occur naturally from moderate sunlight exposure and consumption of fish or systemically from various vitamin $\mathrm{D}$ supplements. ${ }^{10}$

The deficiency of vitamin $\mathrm{D}$ is an international health issue and insufficient exposure to sunlight is the primary cause. Vitamin D has an effect on various systems of the body and there's a receptor for it in every cell in the body. Vitamin D works as a hormone not like other vitamins. Different types of food contain vitamin D, such as fortified dairy products and fatty fish, but sunlight is the primary source of vitamin D. Vitamin $\mathrm{D}$ deficiency is high in geriatrics and females from the Middle East. Factors such as darker skin color, staying indoors, being obese, low consumption of fish and milk products, and kidney or liver diseases are common risk factors related to vitamin D deficiency. Severe vitamin D deficiency could lead to several complications amongst which are body aches, fatigue, myopathy, increased risk of prostate cancer, schizophrenia and cardiovascular disease, to name just a few. ${ }^{11}$

Iron deficiency is considered to be accountable for anemia that affects more than 2 billion people. Alterations in iron levels have a significant effect on the developing individual as they may interfere with their sleep-wake patterns as well as cognitive, motor and socioemotional development. ${ }^{12}$

Iron is known to have an important role in metabolizing monoamines in the brain; therefore, decreased levels of iron may lead to symptoms such as passiveness, lethargy, impatience and negligence. An individual with iron deficiency may incorporate behavioral and emotional traits of individuals with depression.

A valid specific test for iron deficiency is serum ferritin levels in the blood. Due to the importance of iron in the metabolism of monoamines, and the effect of these monoamines on sleep, sleep quality and patterns are known to be affected by iron deficiency. ${ }^{13,14}$

The physiologic ageing process, together with the elderly's stringent diet (iron-poor food) due to their health conditions and their immobility (less vitamin D exposure), is more likely to make elderly adults fall victim to disturbed sleep as compared to the younger adult population. ${ }^{15}$ It is no wonder they are "the ailing population".

Hence, the greater the pain an individual suffers, the greater the detrimental effect on both sleep and overall quality of life. ${ }^{11}$

Even though Saudi Arabia has a sunny environment throughout the year, the majority of Saudis suffer from vitamin D deficiency. The culture and tradition of Saudi Arabians is to dress in the traditional clothing style that covers almost the entire body, in addition to an afternoon siesta and mostly indoor activities and nocturnal hours all aimed at avoiding the sun and heat. ${ }^{16}$

It is pertinent to note that pain adversely affects sleep. It interrupts one's sleep architecture thus impeding the overall sleep replenishment in patients already at a disadvantage from an underlying sleep disorder. Cognition is only one dimension that is affected in acute sleep disorders; there is also a chronic summative effect of sleep deprivation including and not limited to metabolic syndrome, dementia, diabetes and hypertension, amongst others. Therefore for pain to be assessed and addressed, the patient needs to be educated in recognizing the impact of their poor sleep on their overall wellbeing. ${ }^{17}$

This is corroborated by a recent study of 172 middle age adults that showed an increased risk of Type II diabetes and cardiovascular disease in those subjects identified as night owls (evening chronotype). ${ }^{18}$

A systematic review of 29 studies looked at parameters of diet quality, dietary patterns and and sleep quality according to self report and objective records. The results showed a clear association between healthy food 
consumption and improved quality of sleep. Diet-related variables determined sleep quality. ${ }^{19}$

In a recent review, some studies showed an association between obesity and sleep disturbances; obesity increased the risk of sleep disturbance. The latter affects diet and diet affects the duration and quality of sleep disturbance. Hence, nutrition not only helps in improving obesity but can also improve sleep. ${ }^{20}$

The aim of our study is to find the correlation between diminished levels of vitamin D and iron on general pain as well as quality of sleep among healthy Saudi citizens aged between 25 and 55 years of age.

\section{Methods \\ Design}

This is a cross-sectional study, which utilized a closedended online questionnaire. Survey Monkey was used to design the survey.

\section{Study Population}

The study was open for all participants, male and female subjects, between the ages of 25 and 55 years, medically fit and non-pregnant.

Only participants who willingly agreed to complete the entire survey were included. Anonymity of participants was guaranteed. Any survey data that was incomplete was not included.

\section{Ethical Statement}

The study followed the Declaration of Helsinki guidelines and was approved by the Institutional Review Board of Riyadh Elm University, with approval number: FRP/2020/ 209/117/122. Each of the subjects was informed about the purpose of the study prior to participation. The only link that can identify participants was via the consent form, which was coded to guarantee privacy.

\section{Data Collection}

Data was collected during the months of February and March 2020 before the COVID-19 crisis and attained a convenient sample of 3127 responses from participants; only $88.7 \%$ of that total number was included $(n=2774)$ due to missing responses.

\section{Instruments}

1. A 10-item Operator Designed Questionnaire, which included questions about age, gender, social status, nationality, job title, amount of time in the sunlight daily, blood donations in past 6 months, daily intake of multivitamins, iron and vitamin D supplements (Figure 1).

2. A 9-item Sleep Quality Questionnaire ${ }^{21}$ (Figure 2),

5 answers to which were collected on a 5-point interval scale, 4 on a 5-point ordinal scale.

3. A 9-item Brief Pain Inventory Questionnaire ${ }^{22}$ (Figure 3), answers to

6 of which were collected on a 10-point ratio scale, 1 was a shaded area on a human representative diagram, 1 was a 2-point nominal scale, 1 was a 3-point ordinal scale.

\section{Data Analysis}

The data was analyzed using Statistical Package for the Social Sciences (SPSS, Version 21, and SPSS Inc., Chicago, IL, USA) software for Windows to analyze and attain Pearson's correlations and Cronbach's alphas, amongst others. Statistical Significance was set at $\mathrm{p} \leq 0.05$. The power of the sample of our research was $0.87(\mathrm{n}=2774)$, which meant that the majority of the results were statistically significant.

\section{Results}

The Cronbach's alpha coefficient exceeded 0.7, which implied that the questionnaire was reliable for use in further research.

Responses were collected predominantly from females $91.4 \%(\mathrm{n}=2570)$, in the younger age group of 25 to 30 years; $75.6 \%(\mathrm{n}=2096)$. The majority of participants were single $69.8 \%(\mathrm{n}=1968)$ and $73.6 \%(\mathrm{n}=2072)$ claimed to have spent less than 30 minutes a day under the sun (Table 1).

Furthermore, only $3 \%$ of the total sample $(n=86)$ had donated blood in the past 6 months. Multivitamin intake was less than three-quarters of the participants $(19.4 \%, \mathrm{n}=547)$ and vitamin D supplements was even less $(11 \%, \mathrm{n}=310)$ but was close to iron intake $(12.1 \%, \mathrm{n}=341)$ (Table 1).

Pearson's correlations showed a significant positive correlation between sleep quality and intake of iron supplements (p-value: 0.017) (Table 2).

Pearson's correlations showed a significant positive correlation between quality of sleep and time spent in daylight (p-value: 0.009) (Table 2).

There was no significant correlation between iron supplement intake and any pain perception (p-value 0.136) (Table 3).

There was no significant correlation between vitamin $\mathrm{D}$ and any pain perception (p-value: 0.463 ) (Table 3 ). 
Operator Designed Questionnaire

1) Age:

- 25-30

- 31-40

- 41-55

- More than 55

2) Gender:

- Male

- Female

3)Social Status:

- Married

- Single

4) Nationality:

- Saudi

- Non-Saudi

5)Job Title:

- Student

- Government Employee

- Private Employee

- General Physician

- Dentist

- Dental intern

- Non-worker

- House worker

6)How long do you spend in a day in direct sunlight?

- Less than $30 \mathrm{~min}$

- Between $30 \mathrm{~min}$ and an hour

- Between 1 hour to 2 hours

More than 2 hours

7)Did you donate blood in the past 6 months?

- Yes

No

8)Do you take a multivitamin Daily?

- Yes

- No

9)Do you take vitamin D Supplements Daily?

- Yes

- No

10) Do you take Iron Supplements daily?

- Yes
- No

Figure I Operator Designed Questionnaire.

There is a negative correlation between quality of sleep and any kind of pain, which is statistically significant (p-value: 0.000) (Table 4).

\section{Discussion}

Primary Outcome Measures

There was a significant positive correlation between iron intake and sleep quality, bearing in mind that only $12.1 \%$ ( $\mathrm{n}=341)$ of the total $\mathrm{N}=2816$ participants actually took iron supplements.

Furthermore, around $19.4 \%(\mathrm{n}=547)$ of the total $\mathrm{N}=$ 2816 participants claimed to take multivitamins and a mere $3 \%(n=86)$ had donated blood in the past 6 months.

Our study shows a significantl positive correlation between sleep quality and iron supplement intake $(\mathrm{p}<0.17)$. A deficiency in iron has an effect on sleep quality, quantity and timing; iron also affects the modulation of REM sleep. Furthermore, it is reported that iron plays an important role in the myelination of neurons in addition to being a cofactor with tyrosine hydroxylase, which is an integral part of the function of dopamine D2 receptors. ${ }^{13}$ Findings of one randomized controlled trial showed statistically significant findings supporting the benefits of iron supplementation to sleep, overall wellbeing and restless leg syndrome. ${ }^{23}$

There was a significant positive correlation between time spent in the sun and quality of sleep, noting that the majority $(73.6 \%, \mathrm{n}=2072)$ of the total $\mathrm{N}=2816$ participants spent no more than 30 minutes or less a day in the sun. Only an alarming $2.5 \%(\mathrm{n}=73)$ spent 2 or more hours a day, as is the recommended time in our part of the world.

In regards to the integral part of sunlight in vitamin D production, a question regarding sunlight exposure, as $73.6 \%$ of respondents reported spending 30 minutes or less in sunlight, this could be related to in-office nature of work. Furthermore, a significant positive correlation between time spent in daylight and improved sleep quality was found in our research. This finding is supported by a Korean study which reported shorter sleep duration in association with lower vitamin D status in the elderly. ${ }^{24}$

A significant positive correlation between the intake of vitamin D supplements and good sleep quality was noted ( $p<0.054)$. This is supported by a 2018 study, a metaanalysis that reported low serum 25(OH)D could very well be a risk factor for unhealthy sleep and sleep disorders, as the sleep-wake cycle is regulated by vitamin D receptors that are distributed in the hypothalamus, prefrontal cortex, midbrain central gray, substantia nigra and raphe nuclei. ${ }^{25}$ Additionally a further study relates low levels of vitamin D to fragmented sleep and poor sleep quality. ${ }^{26}$ 


\section{QUESTIONNAIRE FOR SLEEP-QUALITY*}

Developed by Colin Espie, Professor of Sleep Medicine, University of Oxford

Circle the most accurate response for each question, thinking about a typical night of sleeping. When you finish, add up your total points to obtain your sleep assessment.

1. How long does it take you to fall asleep?

0-15 min. 4 Points

16-30 min. 3 Points

31-45 min. 2 Points

46-60 min. 1 Point

$>60$ min. $\quad 0$ Points

2. If you wake up one or more times during the night, estimate how long you are awake in total? (add up all the times you are awake.)

0-15 min. 4 Points

16-30 min. 3 Points

31-45 min. 2 Points

46-60 min. 1 Point

$>60$ min. $\quad 0$ Points

3. If your final wake-up time occurs before you intend to wake up, how much earlier is this I don't wake up too early/up to $15 \mathrm{~min}$. early 4 Points

16-30 min. early 3 Points

31-45 min. early 2 Points

46-60 min. early 1 Point

$>60$ min. early 0 Points

4. How would you rate your sleep quality?

$\begin{array}{ll}\text { Very good } & 4 \text { Points } \\ \text { Good } & 3 \text { Points } \\ \text { Average } & 2 \text { Points } \\ \text { Poor } & 1 \text { Point } \\ \text { Very Poor } & 0 \text { Points }\end{array}$

5. How many nights a week do you have a problem with your sleep?

0-1 4 Points

23 Points

32 Points

$4 \quad 1$ Point

5-7 0 Points

Consider the past month, to what extent has poor sleep......

6 . Affected your productivity, concentration, or ability to stay awake?

Not at all 4 Points

A little 3 Points

Somewhat 2 Points

Much 1 Point

Very much 0 Points

Figure 2 Continue. 
7. Affected energy, relationships, or mood?

Not at all 4 Points

A little 3 Points

Somewhat 2 Points

Much 1 Point

Very Much 0 Points

8. Troubled you in general?

Not at all 4 Points

A little 3 Points

Somewhat 2 Points

Much 1 Point

Very Much 0 Points

9. How long have you had a problem with your sleep?

I don't have a problem/<month 4 Points

1-2 months 3 Points

3-6 months 2 Points

7-12 months 1 Point

$>1$ year 0 Points

\section{Scoring Guide}

0-9 Your sleep problems seem to be severe. You should definitely seek help.

10-18 You have some sleep problems. It's important to examine your sleep habits and see how you can make changes.

19-27 Your sleep is in good shape, but there are still many steps you can take to make it even better.

28-36 Your sleep is in great shape. Keep doing what you're doing and spread the word!

*SOURCE: The Sleep Revolution by Arianna Huffington

Resources:

National Sleep Foundation.org

a) Sleep.org

b) CBTI (Cognitive behavioral therapy for insomnia)

\section{$\underline{\text { Apps }}$}

Sleepio: a digital Cognitive Behavioral Therapy Program for sleep Headspace: guided meditation sessions and mindfulness training iSleepEasy: meditations for restful sleep Relax Melodies: choose sleep melodies and mindfulness meditations Relax and Sleep Well: helps you to form healthy sleep habits Tuck me In: Relaxing Yourself to Sleep by Martha Ringer Deep Calm by Dr. Andrew Weil \& Joshua Leeds

\section{Mattresses}

www.organiclivingaz.com (includes mattresses, bedding, and a variety of non-toxic home products/supplies) www.tuftandneedle.com

www.sleepnumber.com

www.tempurpedic.com

www.casper.com

www.leesa.com

Figure 2 Sleep Quality Questionnaire.

Notes: Reproduced from: Huffington A. The Sleep Revolution: Transforming your life, one night at a time. London: WH Allen; $2016 .{ }^{21}$ Copyright $@$ C Arianna Huffington 2016. 
STUDY ID \#:--------- DO NOT WRITE ABOVE THIS LINE HOSPITAL \#:

\section{Brief Pain Inventory (Short Form)}

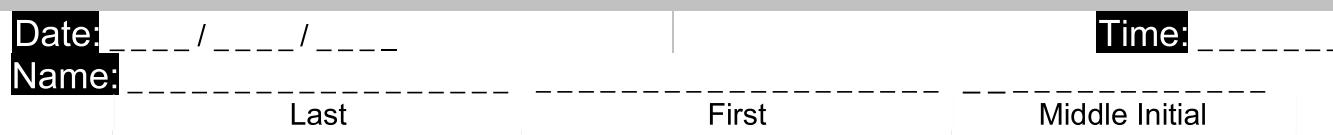

1. Throughout our lives, most of us have had pain from time to time (such as minor headaches, sprains, and toothaches). Have you had pain other than these everyday kinds of pain today?

$$
\text { 1. Yes 2. No }
$$

2. On the diagram, shade in the areas where you feel pain. Put . $X$ on thr area that hurts the most.

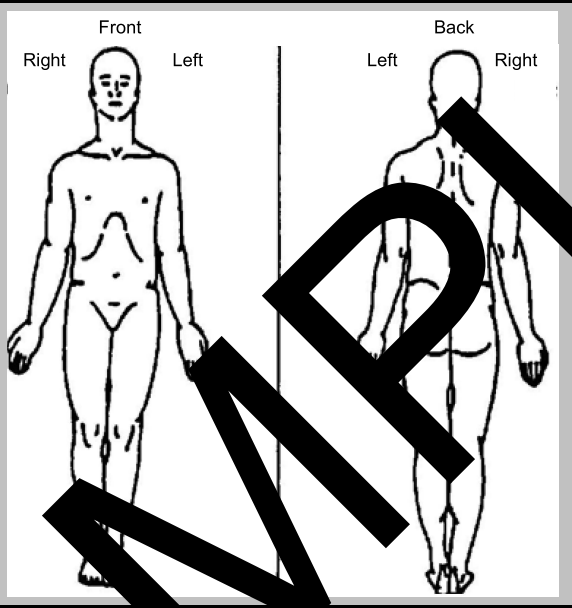

3. Please rate yc ain by circliı. "he one number that best describes your pain at its worst in the las ?.4.

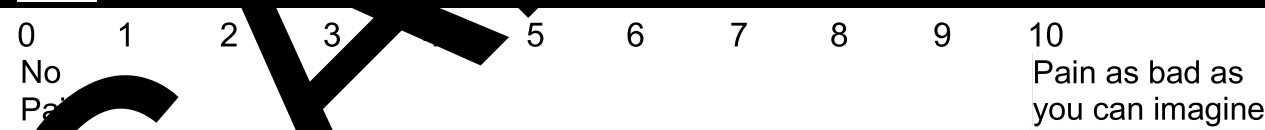

4. I jase rate '...' r pa। jy circling the one number that best describes your pain at its ist in" rdSt "hc is.

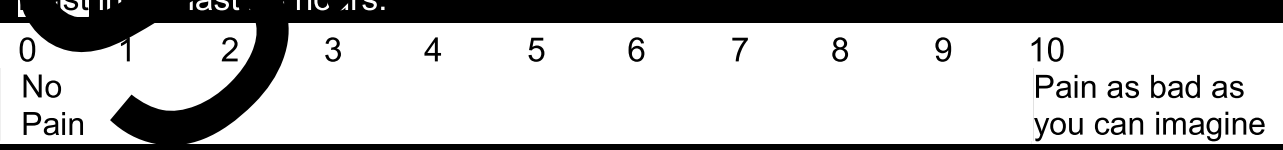

5. Please rate your pain by circling the one number that best describes your pain on the average.

$\begin{array}{lllllllllll}0 & 1 & 2 & 3 & 4 & 5 & 6 & 7 & 8 & 9 & \begin{array}{l}10 \\ \text { Pain as bad as } \\ \text { you can imagine }\end{array} \\ \text { Pain } & & & & & & & & & \\ \text { Par a }\end{array}$

6. Please rate your pain by circling the one number that tells how much pain you have right now.

$\begin{array}{lllllllllll}0 & 1 & 2 & 3 & 4 & 5 & 6 & 7 & 8 & 9 & \begin{array}{l}10 \\ \text { Pain as bad as } \\ \text { you can imagine }\end{array} \\ \text { Pain } & & & & & & & & & & \end{array}$

Page 1 of 2

Figure 3 Continue. 


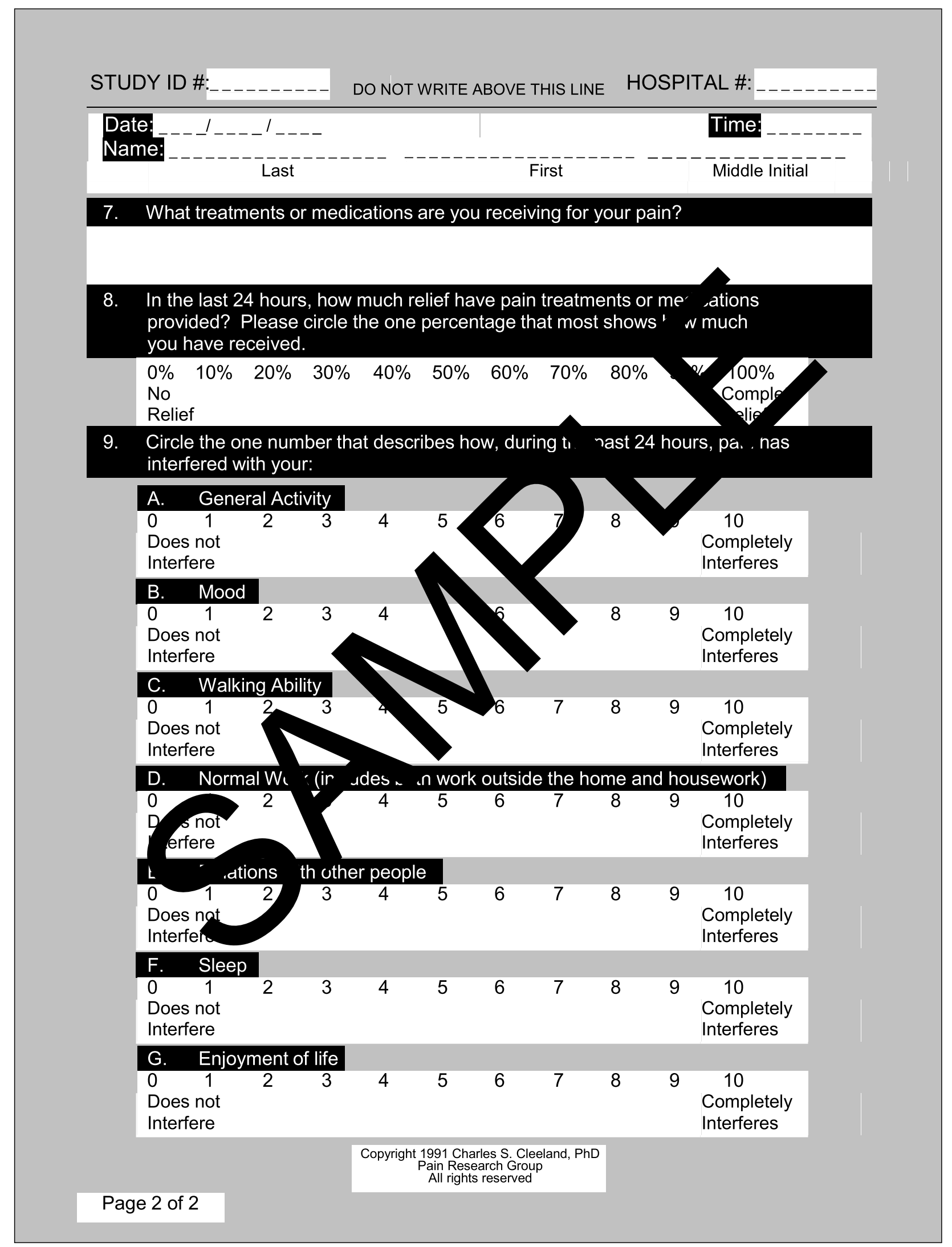

Figure 3 Brief Pain Inventory Questionnaire.

Notes: Reproduced from: Cleeland CS, Ryan KM. Pain Assessment: Global use of the Brief Pain Inventory. Annals, Academy of Medicine, Singapore. 1994;23(2): I29-138. ${ }^{22}$ Copyright I99I, Charles S. Cleeland, PhD; Pain Research Group; All rights reserved. 
Table I Background Characteristics of the Cohort

\begin{tabular}{|c|c|c|}
\hline Sample Characteristics & $\mathbf{n}$ & $\%$ \\
\hline \multicolumn{3}{|l|}{ Age } \\
\hline $25-30$ & 2096 & 75.6 \\
\hline $31-40$ & 305 & 11.0 \\
\hline $4 I-50$ & 283 & 10.2 \\
\hline 55 & 90 & 3.2 \\
\hline Total & 2774 & 100.0 \\
\hline \multicolumn{3}{|l|}{ Donated blood in past 6 months } \\
\hline Yes & 86 & 3.0 \\
\hline No & 2736 & 97.0 \\
\hline Total & 2822 & 100.0 \\
\hline \multicolumn{3}{|l|}{ Multivitamin intake } \\
\hline Yes & 547 & 19.4 \\
\hline No & 2270 & 80.6 \\
\hline Total & 2817 & 100.0 \\
\hline \multicolumn{3}{|l|}{ Vitamin D supplements } \\
\hline Yes & 310 & 89.0 \\
\hline No & 510 & 11.0 \\
\hline Total & 2820 & 100.0 \\
\hline \multicolumn{3}{|l|}{ Iron supplements } \\
\hline Yes & 341 & 12.1 \\
\hline No & 2475 & 87.9 \\
\hline Total & 2816 & 100.0 \\
\hline \multicolumn{3}{|l|}{ Time in the sun } \\
\hline Less than 30 minutes & 2272 & 73.05 \\
\hline Between 30 minutes and I hour & 620 & 19.94 \\
\hline Between I hour and 2 hours & 175 & 5.63 \\
\hline More than 2 hours & 84 & 2.7 \\
\hline Total & 3110 & 100.0 \\
\hline
\end{tabular}

As far as multivitamin intake is concerned, statistically significant differences $(p<0.036)$ were found when the participants were asked to rate the quality of their sleep. It was shown that individuals who did not intake multivitamins are more inclined to rate their sleep as poor or very poor. There were no statistically significant differences when these results were compared with iron supplement intake or vitamin D supplement intake. It was also established that the significant incidences with quality of sleep existed with multivitamins alone $(\mathrm{p}<0.002)$; all other relationships were insignificant. However, an exploratory study on vitamin intake and sleep claims otherwise. ${ }^{27} \mathrm{~A}$ metanalysis of vitamin D deficiency showed a significantly heightened odds risk of a sleep disorder. ${ }^{25}$

\section{Secondary Outcome Measures}

Surprisingly, in this particular cohort, there was no significant correlation between iron supplement intake and any pain perception (p-value: 0.136). Furthermore, there was no significant correlation between vitamin $\mathrm{D}$ and any pain perception (p-value: 0.463 ).

Interestingly, and not surprisingly, there was a negative correlation between quality of sleep and any kind of pain, which was statistically significant (p-value: 0.000 ). That is, sleep quality improves in the absence of pain. A study on fibromyalgia patients reported that the efficacy of inhibitory conditioned pain modulation (ICPM) is significantly correlated with poor sleep and it has an effect on sleep effectiveness. ${ }^{28}$

Table 2 Correlations of Quality of Sleep, Iron, Multivitamins, and Time in Sunlight

\begin{tabular}{|c|c|c|c|c|c|}
\hline & & Quality of Sleep & Multivitamins & Iron Supplements & Time in Sunight \\
\hline \multirow[t]{4}{*}{ Pearson correlation } & Quality of sleep & 1.000 & 0.054 & 0.017 & 0.009 \\
\hline & Multivitamins & 0.054 & 1.000 & 0.409 & 0.030 \\
\hline & Iron supplements & 0.017 & 0.409 & 1.000 & 0.011 \\
\hline & Time in sunlight & 0.009 & 0.030 & 0.011 & 1.000 \\
\hline \multirow[t]{4}{*}{ Sig. (I-tailed) } & Quality of sleep & & 0.002 & 0.190 & 0.318 \\
\hline & Multivitamins & 0.002 & & 0.000 & 0.054 \\
\hline & Iron supplements & 0.190 & 0.000 & & 0.278 \\
\hline & Time in sunlight & 0.318 & 0.054 & 0.278 & \\
\hline \multirow[t]{4}{*}{$\mathrm{N}$} & Quality of sleep & 2795 & 2795 & 2795 & 2795 \\
\hline & Multivitamins & 2795 & 2795 & 2795 & 2795 \\
\hline & Iron supplements & 2795 & 2795 & 2795 & 2795 \\
\hline & Time in sunlight & 2795 & 2795 & 2795 & 2795 \\
\hline
\end{tabular}

Notes: This table shows a significant positive correlation between quality of sleep with iron supplement intake ( $\mathrm{p}$-value: 0.017$)$ and time spent in daylight ( $\mathrm{p}$-value: 0.009 ), multivitamins with time spent in daylight ( $\mathrm{p}$-value: 0.030 ) and taking iron supplements with time spent in daylight ( $\mathrm{p}$-value: $0.0 \mathrm{II})$. 
Table 3 Correlations of Any of Kind of Pain, Iron, Multivitamins, and Time in Sunlight

\begin{tabular}{|c|c|c|c|c|c|}
\hline & & Any Kind of Pain & Multivitamins & Iron Supplements & Time in Sunight \\
\hline \multirow[t]{4}{*}{ Pearson correlation } & Any kind of pain & 1.000 & -0.015 & -0.021 & -0.002 \\
\hline & Multivitamins & -0.015 & 1.000 & 0.412 & 0.030 \\
\hline & Iron supplements & -0.021 & 0.412 & 1.000 & 0.012 \\
\hline & Time in sunlight & -0.002 & 0.030 & 0.012 & 1.000 \\
\hline \multirow{4}{*}{ Sig. (I-tailed) } & Any kind of pain & & 0.208 & 0.136 & 0.463 \\
\hline & Multivitamins & 0.208 & & 0.000 & 0.057 \\
\hline & Iron supplements & 0.136 & 0.000 & & 0.258 \\
\hline & Time in sunlight & 0.463 & 0.057 & 0.258 & \\
\hline \multirow[t]{4}{*}{$N$} & Any kind of pain & 2789 & 2789 & 2789 & 2789 \\
\hline & Multivitamins & 2789 & 2789 & 2789 & 2789 \\
\hline & Iron supplements & 2789 & 2789 & 2789 & 2789 \\
\hline & Time in sunlight & 2789 & 2789 & 2789 & 2789 \\
\hline
\end{tabular}

Notes: Table 3This table shows a significant positive correlation between multivitamins and iron supplements ( $\mathrm{p}$-value: 0.000 ), whereas all other correlations were not statistically significant.

Table 4 Correlation Between Variables of Interest

\begin{tabular}{|l|c|c|}
\hline & Quality of Sleep & Any Kind of Pain \\
\hline Quality of sleep & 1 & $-0.16^{*}$ \\
Any kind of pain & $-0.16^{*}$ & 1 \\
\hline
\end{tabular}

Note: *Correlation is significant at the 0.01 level (2-tailed).

\section{Results as Related to Prior Hypothesis}

The aims and objectives of this study were to determine whether there exists an association in reported levels of iron as well as vitamin D on a person's reported quality of sleep and perception of pain. As per the Results section, our data indeed support that both iron and vitamin $\mathrm{D}$ independently provide better quality of sleep. On the other hand, in this particular cohort, there was no significant effect of iron and vitamin $\mathrm{D}$ on perception of pain.

\section{Strengths and Limitations of the Study}

There is a thirst for studies on iron and vitamin D levels on sleep and pain quality in a part of the world where deficiency is a huge problem. The lack of awareness and knowledge of the relevance of these most basic of minerals and vitamins on one's overall health, in this case sleep and pain, fueled our interest to pursue this research. This research provides a front-row seat to witness the amount of damage and harm that the deficiency of these culprits may have.

Most studies that have been conducted in the Middle East are sparse and are in relation to restless leg syndrome.
There is no study to our knowledge that looked solely at quality of sleep and pain perception. Furthermore, our study uses the validated Sleep Quality Questionnaire ${ }^{21}$ to assess sleep and the Brief Pain Inventory Questionnaire ${ }^{22}$ to assess pain.

There is a scant amount of studies, mainly on vitamin $\mathrm{D}$ and restless leg syndrome, on obesity and not nearly enough to do justice to their foundational role. The limitation of this study is the self-report on both intake in terms of iron and vitamin D and response in terms of sleep and pain. Furthermore, there is no adequate display of female and male participants since the majority of respondents were female $(91.4 \%)$ and only $8.6 \%$ were male; therefore the effects of vitamin $\mathrm{D}$ and iron levels on gender cannot be predicted.

However, the strength of this study lies in its numbers. Since this was a survey type of study, the strength was in numbers of participants and their self-report, not to mention the 2 validated questionnaires assessing sleep and pain. We need to keep in mind that findings from our study might contradict findings of other studies with different patient selection and methodologies.

\section{Interpretations and Implications in the Context of Totality of Evidence}

Iron cofactors with tyrosine hydroxylase, which is integral for D2 receptor function.

D2 receptor function is important in sleep. D2 receptor availability helps with wakefulness; that is, a decrease in D2 receptors is associated with sleepiness. 
The lack of the dopamine transporter gene increases wakefulness; similarly, lacking the D2 receptor decreases wakefulness (increases sleep) ${ }^{29}$

Moreover, iron deficiency causes long-lasting changes in the temporal framework of sleep patterns, which have a negative effect on a person's overall health. ${ }^{12}$

In a study conducted in Turkey, an area of the world in close proximity to the Middle East, there was a significant role of iron deficiency anemia on sleep quality. Around $68 \%(\mathrm{n}=70)$ of the total $(\mathrm{N}=104)$ patients with iron deficiency anemia exhibited a form of sleep impairment. ${ }^{13}$ These same participants had significant sleep problems and more than double the controls had reported bad sleep quality ( $\mathrm{n}=70$ case, $\mathrm{n}=32$, respectively) and this was statistically significant $(\mathrm{p}<0.001)$. This was evaluated using the Pittsburgh Sleep Quality Index (PSQI). Furthermore, the sleep latency, habitual sleep efficiency, sleep disturbance, general dysfunction, and total sleep disorder scores between cases of iron deficiency and controls had statistically significant differences, with negative effects on the former.

This is similar to the results of our study: those who did not report iron supplement intake also reported poorer quality of sleep than their iron supplement counterparts.

A recent metaanalysis of vitamin D deficiency and sleep disorders showed astounding effects. Those with vitamin $\mathrm{D}$ deficiency were 1.5 times more likely to have a sleep disorder; poorer sleep quality (OR: 1.59), shorter sleep duration (OR: 1.74), and increased sleepiness (OR: 1.36). ${ }^{25}$

A further testimony in the literature, a double-blind clinical study conducted in Tehran on patients with sleep disorders, showed a remarkable improvement in both sleep quality and duration after a mere 8 weeks of vitamin D supplementation (50,000 IU every 2 weeks). ${ }^{30}$

The negative correlation found in our study between sleep quality and pain is evidenced in a metaanalysis of nearly 5902 participants with a 2- and 5-year follow up that demonstrated persistent poor sleep and increased reports of pain in $66 \%$ of those participants. ${ }^{31}$

\section{Controversies Raised by This Study}

Iron deficiency is a most serious global health concern that affects around a third of the world's population. ${ }^{32}$

There are no studies found in the literature showing a direct relationship between iron deficiency and pain per se. We hypothesized that, since iron deficiency affects sleep patterns, then in turn, pain perception would be heightened. ${ }^{33}$
Furthermore, there is solid evidence of long-term effects of iron deficiency at infancy continuing into adulthood along with all the abnormalities be they demyelination and/or sleep disturbance, amongst others. ${ }^{34}$

Our study found no statistical significance between low iron levels and heightened reports of pain perception.

Prevalence of vitamin D deficiency is at its highest in Saudi Arabia in females of child-bearing age, in relevance to other countries within the Middle East. ${ }^{35}$

One would assume that report of pain would be significant in our study; however, there was no such effect, despite the many studies that show a relationship between vitamin D deficiency and pain. ${ }^{25}$

We must bear in mind that our study is conducted in a different population, it was a survey and most of the participants were young and healthy. However, the literature is laced with concrete evidence between vitamin $\mathrm{D}$ deficiency and pain. There is a definite link between depleted levels of vitamin $\mathrm{D}$ and pain, since pain is affected by sleep and sleep is affected by vitamin D. ${ }^{36}$ There are inflammatory markers associated with pain and sleep deprivation, such as IL-6. ${ }^{37}$ Low vitamin D and IL-6 are found in patients suffering from obstructive sleep apnea. ${ }^{38}$

Our correlation between quality of sleep and any kind of pain was a significant negative correlation meaning that as reports of sleep quality become poor, the report of pain becomes higher.

\section{Future Research Directions}

This study was conducted to determine the association of self-reported iron and vitamin D levels with sleep quality and pain perception.

Corroboration of this study's results should be tested using a similar population with equal distribution of males and females, randomly selected, with additional tests that are objectively documenting their iron and vitamin D levels, together with their sleep and pain status.

\section{Conclusion}

To conclude, our study corroborates the current research identifying a significant correlation between reports of iron and vitamin D levels on sleep quality. We assumed that poor sleep would in turn lower one's threshold to pain. This was a significant correlation in our study; however, the deficiency independently in each of iron and vitamin D had no such effect on pain. This might be due to our population which was relatively young (25-30) and age is an important factor 
that plays a pivotal role in pain perception, especially when sleep is involved. The world today is plagued by a fast-paced life, with hours of screen time and diminished time in the outdoors where key elements essential for a healthy life are being overlooked, the most basic of which is sunlight.

\section{Recommendation}

Many factors mediate one's quality of sleep, including but not limited to the amount of vitamin D obtained from sunlight, consumption of multivitamins, vitamin $\mathrm{D}$ and iron supplements. Additionally, there is a multimode effect of poor sleep, which in turn lowers the pain threshold thus increasing one's sensitivity to and awareness of pain in an otherwise healthy individual. As health care professionals, addressing our patients as a whole entity and their quality of life may have a direct impact on the amount of prescription drugs dispensed and procedures set.

\section{Data Sharing Statement}

The data is available upon request from the corresponding author.

\section{Ethical Policy and Institutional Review Board Statement}

The Institutional Review Board of Riyadh Elm University approved the conduct of this study following its registration FRP/2020/209/117 and similarly its approval, FRP/ 2020/209/117/122.

\section{Patient Declaration of Consent}

The authors certify that consent was obtained in the opening page of the questionnaire; each participant had the choice of dismissing or completing the questionnaire without any risk of identity disclosure.

\section{Acknowledgments}

The authors sincerely appreciate the participation of all subjects who kindly took the time and patience to complete the questionnaire.

\section{Author Contributions}

All authors contributed to data analysis, drafting or revising the article, have agreed on the journal to which the article will be submitted, gave final approval of the version to be published, and agree to be accountable for all aspects of the work.

\section{Funding}

There was no financial support and funding for this study.

\section{Disclosure}

The authors report no conflicts of interest for this work.

\section{References}

1. Shepard JW, Buysse DJ, Chesson AL, et al. History of the development of sleep medicine in the United States. $J$ Clin Sleep Med. 2005;1(1):61-82. doi:10.5664/jcsm.26298

2. Karatay G, Bas NG, Aldemir H, Akay M, Bayir M, Onayli E. Examining the sleep habits of nursing department students and the affective factors. HSP. 2016;3(1):16-22.

3. Hirshkowitz M, Whiton K, Albert SM, et al. National Sleep Foundation's sleep time duration recommendations: methodology and results summary. Sleep Health. 2015;1(1):40-43. doi:10.1016/j. sleh.2014.12.010

4. Constitution of the World Health Organization. World Health Organization: Basic Documents. 45th ed. Geneva: World Health Organization; 2005.

5. Watson NF, Badr MS, Belenky G, et al. Recommended amount of sleep for a healthy adult: a joint consensus statement of the American Academy of Sleep Medicine and Sleep Research Society. $J$ Clin Sleep Med. 2015;11(6):591-592. doi:10.5664/jcsm.4758

6. Peirano PD, Algarín CR, Garrido MI, Lozoff B. Iron deficiency anemia in infancy is associated with altered temporal organization of sleep states in childhood. Pediatr Res. 2007;62:715-719. doi:10.1203/PDR.0b013e3181586aef

7. Ibanez V, Silva J, Cauli O. A survey on sleep assessment methods. A survey on sleep assessment methods. Peer J. 2018;6:e4849. doi: 10.7717 peerj. 4849

8. Abou-Khadra MK, Amin OR, Shaker OG, Rabah TM. Parentreported sleep problems, symptom ratings, and serum ferritin levels in children with attention-deficit/hyperactivity disorder: a case control study. BMC Pediatr. 2013;13:217. doi:10.1186/1471-2431-13217

9. McCarty DE, Reddy A, Keigley Q, Kim PY, Marino AA. Vitamin D, race, and excessive daytime sleepiness. JCSM. 2012;8(6):693-697. doi: $10.5664 / \mathrm{jcsm} .2266$

10. Van Schoor NM, Lips P. Worldwide vitamin D status. Best Pract Res Clin Endocrinol Metab. 2011;25(4):671-680. doi:10.1016/j. beem.2011.06.007

11. Neto NSR, de Barros Bento JC, Rodrigues Pereira RM. Depression, sleep disturbances, pain, disability and quality of life in Brazilian Fabry disease patients. Mol Genet Metabol Rep. 2019;22:100547. doi:10.1016/j.ymgmr.2019.100547

12. Peiranoa PD, Algarin CR, Chamorro RA, et al. Sleep alterations and iron deficiency anemia in infancy. Sleep Med. 2010;11(7):637-642. doi:10.1016/j.sleep.2010.03.014

13. Murat S, Ali U, Serdal K, et al. Assessment of subjective sleep quality in iron deficiency anaemia. Afr Health Sci. 2015;15 (2):621-627. doi:10.4314/ahs.v15i2.40

14. Okan S, Cagliyan Turk A, Sivgin H, Ozsoy F, Okan F. Association of ferritin levels with depression, anxiety, sleep quality, and physical functioning in patients with fibromyalgia syndrome: a cross-sectional study. Croat Med J. 2019;60(6):515-520. doi:10.3325/ cmj.2019.60.515

15. Stefan L, Vrgoc G, Rupcic T, Sporis G, Sekulic D. Sleep duration and sleep quality are associated with physical activity in elderly people living in nursing homes. Int J Environ Res Public Health. 2018;15 (11):2512. doi:10.3390/ijerph15112512 
16. Farhat KH, Arafa MA, Rabah DM, Amin HS, Ibrahim NK. Vitamin D status and its correlates in Saudi male population. BMC Public Health. 2019;19:211. doi:10.1186/s12889-019-6527-5

17. Marshansky S, Mayer P, Rizzo D, Baltzan M, Denis R, Lavigne GJ. Sleep, chronic pain, and opioid risk for apnea. Prog Neuro Psychopharmacol Biol Psychiatr. 2017;87(Pt B):234-244.

18. Muscogiuri G, Barrea L, Aprano S, et al. Chronotype and cardio metabolic health in obesity: does nutrition matter? Int $J$ Food Sci Nutr. 2021;1-9. doi:10.1080/09637486.2021.1885017

19. Godos J, Grosso G, Castellano S, Galvano F, Caraci F, Ferri R. Association between diet and sleep quality: a systematic review. Sleep Med Rev. 2021;57:101430. doi:10.1016/j.smrv.2021.101430

20. Castellucci B, Barrea L, Laudisio D, et al. Improving sleep disturbances in obesity by nutritional strategies: review of current evidence and practical guide. Int J Food Sci Nutr. 2021;72(5):579-591. doi:10.1080/09637486.2020.1851659

21. Huffington A. The Sleep Revolution: Transforming Your Life, One Night at a Time. New York: Harmony; 2016.

22. Cleeland CS, Ryan KM. Pain assessment: global use of the brief pain inventory. Ann Acad Med. 1994;23(2):129-138.

23. Macher S, Herster C, Holter M, et al. The effect of parenteral or oral iron supplementation on fatigue, sleep, quality of life and restless legs syndrome in iron-deficient blood donors: a secondary analysis of the IronWoMan RCT. Nutrients. 2020;12(5):1-15. doi:10.3390/ nu12051313

24. Kim JH, Chang JH, Kim DY, Kang JW. Association between self-reported sleep duration and serum vitamin D level in elderly Korean adults. J Am Geriatr Soc. 2014;62:2327-2332. doi:10.1111/ jgs. 13148

25. Gao Q, Kou T, Zhuang B, Ren Y, Dong X, Wang Q. The association between vitamin D deficiency and sleep disorders: a systematic review and meta-analysis. Nutrients. 2018;10(10):1395. doi:10.3390/nu10101395

26. Muscogiuri G, Barrea L, Scannapieco M, et al. The lullaby of the sun: the role of vitamin D in sleep disturbance. Sleep Med. 2019;54:262-265. doi:10.1016/j.sleep.2018.10.033

27. Lichstein KL, Payne KL, Soeffing JP, et al. Vitamins and sleep: an exploratory study. Sleep Med. 2008;9(1):27-32. doi:10.1016/j. sleep.2006.12.009
28. Paul-Savoie E, Marchand S, Morin M, et al. Is the deficit in Pain Inhibition in Fibromyalgia influenced by sleep impairments? Open Rheumatol J. 2012;6:296-302. doi:10.2174/1874312901206010296

29. Lim MM, Xu J, Holtzman DM, Mach RH. Sleep deprivation potentially affects dopamine receptor subtypes in mouse striatum. Neuroreport. 2011;22(10):489-493. doi:10.1097/WNR.0b013e3 $2834846 \mathrm{a} 0$

30. Shahi MM, Hosseini SA, Helli B, Haghighyzade MH, Abolfathi M. The effect of vitamin d supplement on quality of sleep in adult people with sleep disorders. Tehran Univ Med J. 2017;75:443-448.

31. Afolalu EF, Ramlee F, Tang NKY. Effects of sleep changes on pain-related health outcomes in the general population: a systematic review of longitudinal studies with exploratory meta-analysis. Sleep Med Rev. 2018;39:82-97. doi:10.1016/j.smrv.2017.08.001

32. Kassebaum NJ, Jasrasaria R, Naghavi M, et al. A systematic analysis of global anemia burden from 1990 to 2010. Blood. 2014;123:615-624. doi:10.1182/blood-2013-06-508325

33. Lozoff B, Beard J, Connor J, Barbara F, Georgieff M, Schallert T. Longlasting neural and behavioral effects of iron deficiency in infancy. Nutr Rev. 2006;64:S34-43-91. doi:10.1301/nr.2006.may.S34-S43

34. Lukowski AF, Koss M, Burden MJ, et al. Iron deficiency in infancy and neurocognitive functioning at 19 years: evidence of long-term deficits in executive function and recognition memory. Nutr Neurosci. 2010;13:54-70. doi:10.1179/147683010X12611460763689

35. Al-Daghri NM, Aljohani N, Al-Attas OS, et al. Dairy products consumption and serum 25-hydroxyvitamin D level in Saudi children and adults. Int J Clin Exp Pathol. 2015;8:8480-8486.

36. Haack M, Sanchez E, Mullington JM. Elevated inflammatory markers in response to prolonged sleep restriction are associated with increased pain experience in healthy volunteers. Sleep. 2007;30:1145. doi:10.1093/sleep/30.9.1145

37. Yokoe T, Minoguchi K, Matsuo H. Elevated levels of c-reactive protein and interleukin- 6 in patients with obstructive sleep apnea syndrome are decreased by nasal continuous positive airway pressure. Circulation. 2003;107:1129-1134. doi:10.1161/01. CIR.0000052627.99976.18

38. Zittermann A. Vitamin d in preventive medicine: are we ignoring the evidence? Br J Nutr. 2003;89:552-572. doi:10.1079/BJN2003837
Risk Management and Healthcare Policy

\section{Publish your work in this journal}

Risk Management and Healthcare Policy is an international, peerreviewed, open access journal focusing on all aspects of public health, policy, and preventative measures to promote good health and improve morbidity and mortality in the population. The journal welcomes submitted papers covering original research, basic science, clinical \& epidemiological studies, reviews and evaluations, guidelines, expert opinion and commentary, case reports and extended reports. The manuscript management system is completely online and includes a very quick and fair peer-review system, which is all easy to use. Visit http://www.dovepress.com/testimonials.php to read real quotes from published authors. 